\title{
Women Participation in Automobile Industry: Challenges \& Road Ahead
}

\author{
Ms. Sunita Naik ${ }^{1}$, Mita Mehta ${ }^{2}$, Arti Chandani $^{3}$ \\ \{ sunita.naikpgadm1819@sims.edu ${ }^{1}$ and mita.mehta@sims.edu ${ }^{2}$, \\ arti.chandani@sims.edu ${ }^{3}$ \} \\ Symbiosis Institute of Management Studies (Sims) Symbiosis International (Deemed University) ${ }^{1,2,3}$
}

\begin{abstract}
The purpose of the study was to understand the women participation in automotive industry and to understand the challenges faced by the women. The study also helps to understand the path ahead to overcome the difficulties in automotive industry. A sample size of 50 respondents was chosen. Questionnaires were distributed to the chosen sample size. The respondents belonged to the age group of 25 to 38 years of women working in automotive industry. Apart from primary data, secondary data was collected of the last five years. Based on the respondents' data, it was found that that majority of the women have faced challenges of adjusting to the automotive industry. Gender sensitization, flexi-timings, maternity supports were suggested as the way forward to overcome the unseen barriers. There should be extended maternity leaves in case of complications and crèche facilities. The gender sensitization training should be given to all employees in order to create a conducive environment at workplace. This study will help manufacturers of automobiles in setting better policies.
\end{abstract}

Keywords: Women, Automobiles, Challenges, Gender, Policies

\section{INTRODUCTION}

Gender diversity is a growing necessity in all industries. It has been found out that organization with healthy gender ratios earn better profits. Women add a different dimension in decision making. Gone are the days when women were perceived to be restricted to few jobs. There are women studying engineering and aspiring to be a part of automotive industry. There are several talented women who tend to avoid pursuing career in automobile sector. There are various challenges which has led to such thinking. There is a dearth of woman employment in the automobile industry in India according to the survey by Deloitte. Further, the retention of the few women employed is tougher. India is a progressive country and it is high time to involve more of the woman workforce in the automobile industries.

According to a study done by the Center of Talent Innovation (CTI), the organizations which have greater diversity, have 45 percent higher chances to grow their market share every year. They have higher probability, almost 70 percent, to capture a new market. The study credits diversity that stems from both inherent traits such as gender, ethnicity as well as from acquired traits, or those earned through experience, for unlocking innovation by creating an environment where new and sometimes unexpected ideas are not only voiced, but actually heard. Further, women stick longer to the industry if they are given stable and right environment to work. 
Automobile is a gender-neutral product. So, men and women should work together in the design and manufacturing of automobiles because it adds different dimensions to the product, which will be widely accepted and purchased by consumers. This helps to generate revenue and increase profitability of the organization. But certainly, there is a road ahead for women to engage, enrich and prosper in automobile industry. Earlier, the automotive careers have been restricted to men. But the days have changed, and women have a lot of opportunity to have a career in automotive. In the last decade, the Indian women have had a transition in mindset and job perspectives. India's automotive industry is in the right position for growth. It is capable of domestic as well as export opportunities.

\subsection{Background}

The word automotive has a Greek and Latin origin. Automotive consists of two parts: Greek word "autos" which means "self" and Latin word "motives" which means "of motion". In the early days, it referred to a vehicle which is self-powered, unlike horse driven carriages. Those days, there limited variety of vehicles. Today, there are a variety of automobiles across the globe to cater to the choices of various customers. The Auto Expos gives a glimpse of the journey of automobiles over the years. The automotive industry encompasses the companies which does the research and development for making motor vehicles, and then manufacture and market their vehicles. They are also known as auto maker. Acker J.(1990) argues that assumptions about gender underlie documents and contracts used to construct organizations and to provide commonsense ground for theorizing about them.[1]

In India, in the mid-1940s Indian automotive players like Tata Motors, Mahindra \& Mahindra and Ashok Leyland were born. Further, Maruti Suzuki, Mercedes Benz, Ford Motor Company, Hyundai, BMW, Audi, Land Rover, Jaguar were also manufactured in India. Apart from that there are many suppliers of automotive parts like Delphi, Bosch, and Henkel to name the least. After the globalization in 1991, the automotive players have been more competitive and holding themselves up to global standards. From the initial days, the automotive sector has been thought of as a masculine place. The environment created in the workplace is more oriented towards masculine choices. Although there are women who are engineers and managers, yet they are not sustaining in automobile industry. Like study conducted by Allen suggested that to demonstrate the value of eliciting insight from an 'outsider within' [2], here for this research also such base has been taken. This study revolves around the challenges faced my woman and the steps to rise above them. The penetration of women in automotive industry is very low, especially in the shop-floor. It has been proven that diversity generates profitability. We also intent to found the barriers that are still prevailing to restrict female to promote and lead ahead. [3] Hence women employee would have lesser chance of promotion [4]

On July 23rd 2015, one of the Senior women executive participant in the North American Automotive Industry Executive Roundtable, said that, "The idea of working in the automotive industry suffers from a perception problem." 


\section{Literature Review}

The following literature reviews were done:

1) Deloitte and Automotive News had done a research on women in automobiles on the topic, "Women at the wheel: Recruitment, retention, and advancement of women in the automotive industry" in the year 2015 by Craig Giffi, Joshep Vitale, Ben Dollar, Steve Schmith, Jason Stein, Michelle D. Rodriguez, BharathGangula. The key findings of the research include data collections from women in automotive industry, reasons for difficulty of retention in the industry, relationship between diversity and profitability and the path ahead.

2) Dr (Mrs) Muneer Sultana,Suhaidah Hussain ,Samsudin Shafii, has done a research on "Women Professionals' in Automotive Industry through International College of Automotive (ICAM), Pekan, Malaysia." In the year 2013 did a research on "Women Professionals' in Automotive Industry through International College of Automotive (ICAM), Pekan, Malaysia.”. The key findings are the potential of women to participate in automotive industry and interests of girls' student in automotive jobs.

3) Sharon Carty and Amy Wilson had mentioned in the Automotive News in "Sexism in the Auto Industry Survey", [11] where they did a survey on women in automotive. It mentions about the bias, stereotypes and discomfort. It talks about how women are termed as bossy and aggressive if they stress on their ideas and viewpoint, which makes some women to back out from major decision-making. [10]

4) In Indian Express, Farah Moloobhai mentioned in "Women's journey in automotive and her story" in the year 2017, about how she was let down in meetings/discussion because she is woman, was mocked for her big built and how she used criticism as her strength. This is similar to earlier studies conducted which says that family and other factors are critical for women to be on top. [5]

5) In AutoCar, in 2013, it mentioned about gender diversity in the automobile industry. It describes how gender gap is reducing and how diversity increases productivity. This emphasis on how adaptation of the workplace as a site for embracing culture and promoting gender equity. [8]

6) Deborah Gillis, in 2017, in her blog "Sexual Harassment: Enough is enough", where she mentions how organizations should take up zero tolerance policy, and how victims of harassment are affected and tend to engage less and hinders their career growth. Sometimes sexual and racial standpoint also makes significant influence on women journey. [6] Also sometime women also feel the though in spite of absence of discrimination navigate working life to manage sexualized and discriminatory encounters and comments. [7]

7) Caitlin Kelly, in 2013, mentions in The New York times about "A Woman's touch: Still a rarity in car design", about car designing being predominantly taken by man's decision. 
8) According to Marina Shoemaker (2011) mentioned that the General Motors Women's Retail Network the first automaker in the industry is to establish a program to actively recruit women into the automotive retail field as part of efforts to rise the number of women dealers in network and is launching a scholarship program to encourage women to consider a career in automotive retail.

\section{$3 \quad$ Research Methodology}

\subsection{Selection of topic}

The topic selected is "Women in automotive industry: Challenges and Road Ahead". The study revolves around the journey of automotive industry in India and the involvement of women in the industry. The challenges and the way forward is addressed.

\subsection{Research Objective}

To understand women participation in automotive industry and to recommend positive directions

\subsection{Data}

For this research primary and secondary data has been collated and presented in graphs and charts.

\subsection{Sample size and type}

The sample size has been taken keeping in mind women working in automotive industry, having at least 3 years of experience.

\subsection{Primary sample profile}

A sample size of 50 respondents. The sample type includes women working in automotive industry.

\subsection{Research questions:}

a) What are the challenges for women in Indian automotive industry?

b) What is the road ahead for women in Indian automotive industry?

\subsection{Collection of data}

a) Primary Data: Questionnaire was made and shared to 50 respondents who shared their responses.

b) Secondary Data: This data was collected from online sources of last five years (20132018).

\subsection{Analysis of data}

a) Secondary data has been plotted with inferences 
b) The data obtained through primary sources has been presented in tables and figures and discussed.

\section{Data Analysis}

\section{A) Secondary Data}

1) According to Deloitte Survey of women in automotive in the year 2015, the following reasons where stated as major factors for avoiding careers in automotive:

Table 1 Women in Automotive Industry

\begin{tabular}{|c|l|c|}
\hline Sr. No. & \multicolumn{1}{|c|}{ Description } & Percentage \\
\hline 1 & Poor work- life balance & 89 \\
\hline 2 & Uncomfortable environment for women & 64 \\
\hline 3 & Unavailability of flexible schedule & 61 \\
\hline 4 & Lack of advancement opportunities & 44 \\
\hline 5 & Unattractive income/pay & 24 \\
\hline
\end{tabular}

Inference: Majority of women avoid careers in the automotive industry because of issues related to work-life balance and work environment. This also calls for social change [12]

2) According to Deloitte Survey of women in automotive in the year 2015, $75 \%$ women in automotive felt underrepresented. The following reasons were given for such feeling: ${ }^{1}$

Table 2 Reasons for women being underrepresented

\begin{tabular}{|c|l|c|}
\hline Sr. No. & \multicolumn{1}{|c|}{ Description } & Percentage \\
\hline 1 & $\begin{array}{l}\text { Men are preferred over women for leadership } \\
\text { position }\end{array}$ & 76 \\
\hline 2 & The culture of the organization & 53 \\
\hline 3 & Poor mentorship & 46 \\
\hline
\end{tabular}

\section{Inference:}

Majority of women in automotive felt underrepresented because of industry bias towards men for leadership position followed by culture of the organization as well as poor mentorship. Women and men are different in their leadership style has been criticized by many authors [13].

3) According to Deloitte Survey of women in automotive in the year 2015, these were the following points were mentioned as path ahead:

\footnotetext{
${ }^{1}$ Retrieved from: https://www2.deloitte.com/content/dam/Deloitte/us/Documents/manufacturing/usauto-100-leading-women.pdf Accessed on 22nd August 2018
} 
a) Involvement of top-level employees: The change in culture starts from C-suite. The top management should consider gender diversity and inclusion of women as a business priority. They should set a visible example to the employees, so that the organization aligns themselves with initiatives of gender diversity and inclusion of women. A shift in mindset and vision from the top will penetrate to the bottom level.

b) Creation of more flexible work environment: Lack of work-life balance is deterring factor for women in long-term. Flexible work timings are essential. The organization should consider enhancing and enriching the workforce.

c) Promotion of personal advancement: Women should be given challenging and interesting assignments. They should be given key roles in order to have personal advancement. Women in automotive tend to remain stagnant and hence difficult to sustain themselves.

d) Mentorship: It was found that majority of the women said that there should be program for mentoring women. For instance, women should be given guidance for their career growth and also personal development. This will help women to sustain longer in the organization. This will help to enhance the presence of women within the organization.

4. According to the Automotive News, the survey shows that

a) More than $50 \%$ of the respondents were not satisfied by the response received on filing a complaint.

b) More than $50 \%$ of the respondents were termed as bossy and aggressive when they tried to put forward their viewpoint.

c) More than $50 \%$ said they took shorter maternity leave so that it does not have a negative impact on their career.

d) Nearly $50 \%$ after resuming from maternity leave, they were not considered for important assignments.

e) Nearly $60 \%$ of women stated that being a parent had a negative effect on their career 


\section{Data Analysis}

1) Attractiveness of auto industry for women employees



Figure 1 Attraction of women in different sector/Industry (Source: Automotive News)

Inference: It shows only $1 \%$ of women are attracted towards automotive industry. Whereas other majority of women get attracted to other sectors especially education sector.

2) Women referring other women to be member / part of automotive industry

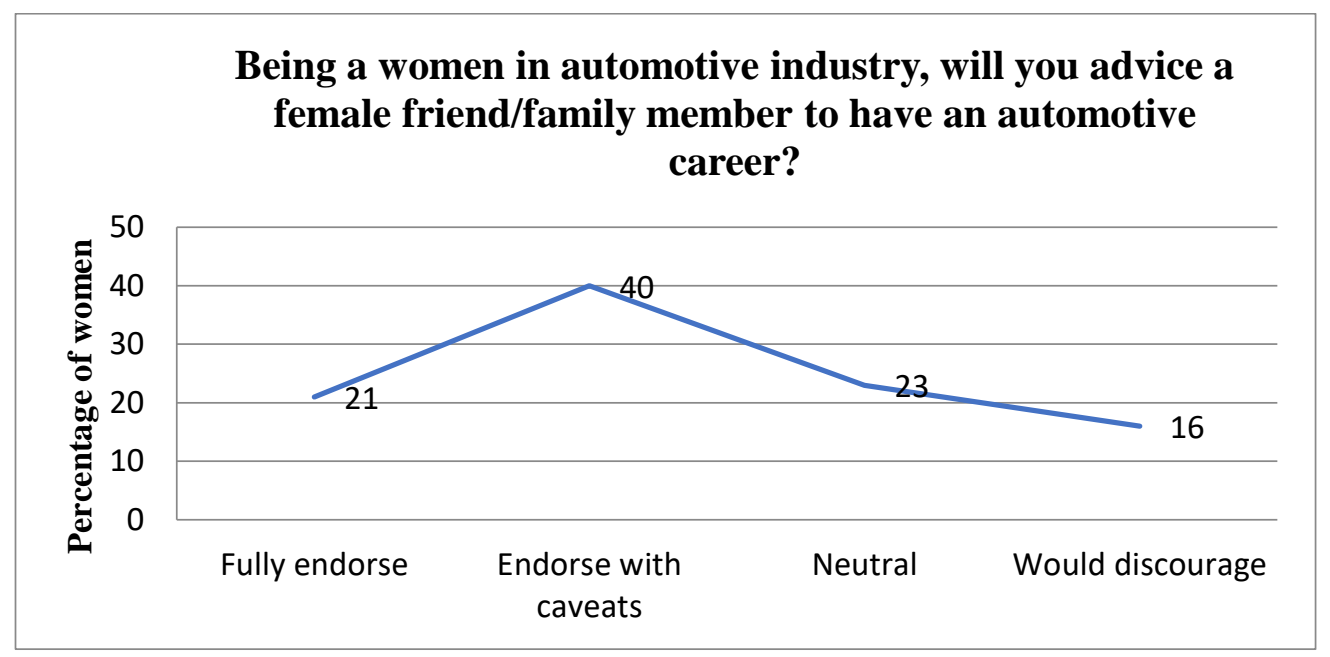

Figure 2 Referring Automotive sector to other female 
Inference: Only $21 \%$ of the women working in automotive will fully endorse any female friend or family member to make a career in automotive industry.

\section{B) Primary Data}

The primary data was collected using one set of questionnaire. The responses of the respondents are mentioned below:

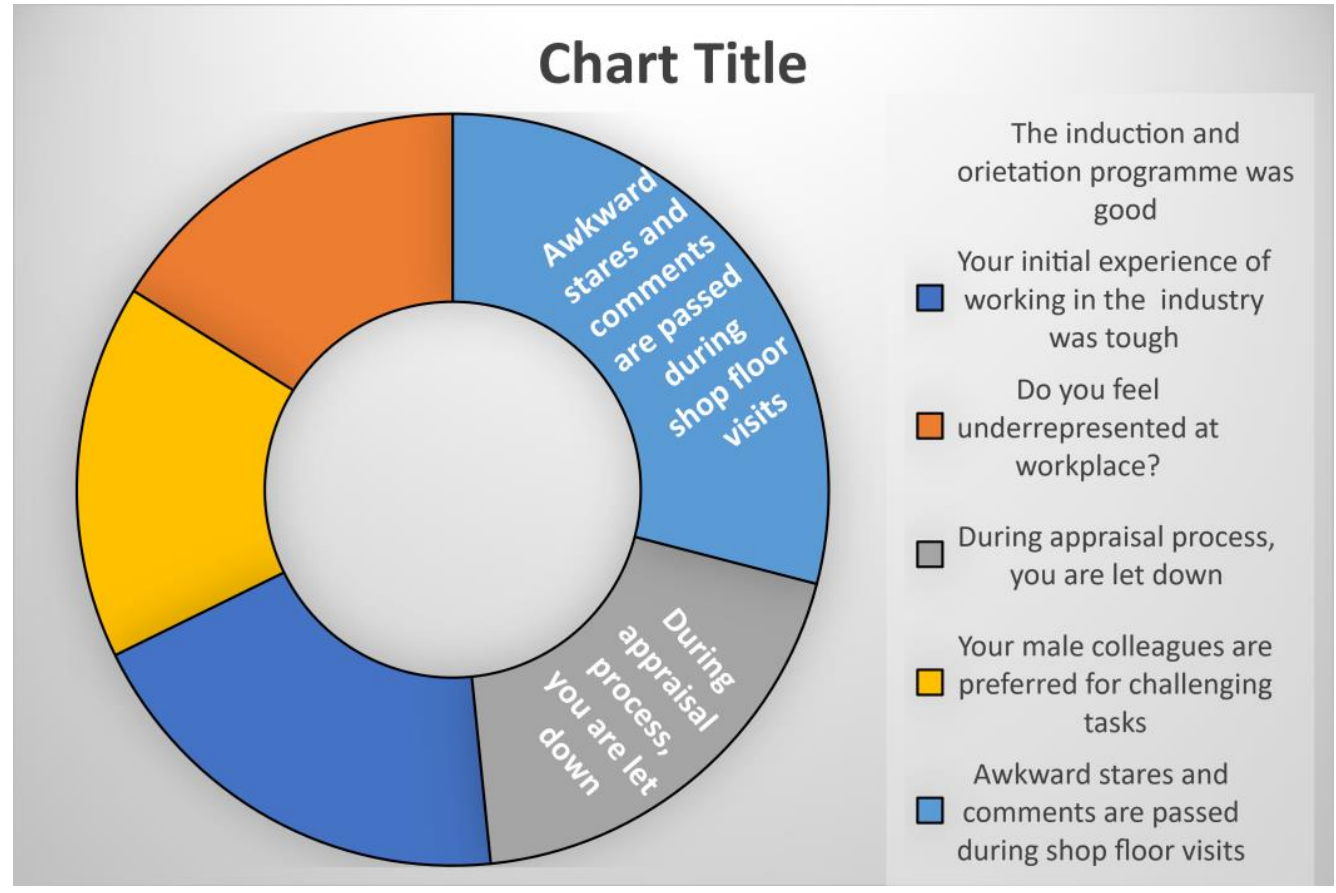

Figure 3. Response of respondents (Collective response of all questions)

Discussion: All the respondents are working in the automotive industry. Majority of the respondents agree that they had a good induction and orientation programme. But the initial experience in the workplace was tough. Further, they felt underrepresented and not given challenging roles. Shop floor visits are not comfortable because of awkward stares by operators. Most of them said that HR was unable to handle women-centric issues. 


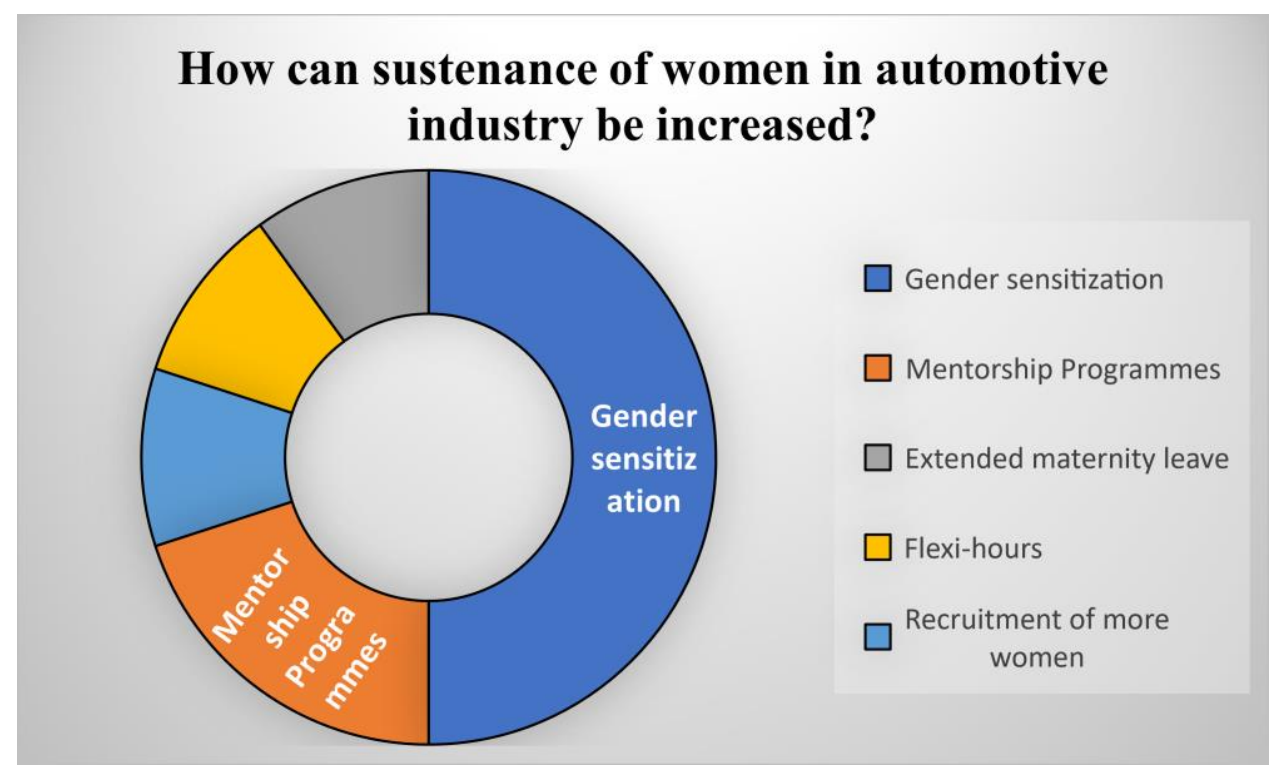

Figure 4. How can sustenance of women in automotive industry be increased?

Discussion: Majority of the respondents said that gender sensitization was an effective method to overcome the challenges. Some suggested, mentorship programme, extended maternity leave, flexi-hours and recruitment of more women.

\section{Challenges}

a) Work-life balance: There is lack of support from organization for women to sustain longer in the industry. The set-up is more masculine in nature with less focus on women-centric development. Work-life balance is a vital part of an organization. Better work-life of employees increases their longevity in the organization. Compared to other sectors, automotive industry has poor work-life balance, especially for women.

b) Unattractive environment for work: Being a male-dominated industry, women are usually uncomfortable in the offices and assembly lines. It may be due to awkward conversations, habits (like smoking) or even awkward stares. This also leads to poor work relations which further affects the networking of women. It has also been reported that some of the senior managers also make displeasing comments or approaches. Since, they are senior in hierarchy, they avoid replying back. This further increases the displeasing comments, which leads to mental harassment. It had been found that especially store rooms and paint shop, where it a closed surroundings women feel uncomfortable. It has been reported that when women hear comments like, "Even if scream from here, no one can hear". There may not be any actual sexual harassment, but it creates a sense of fear and discomfort. This leads to less engagement at work.

c) Fixed schedule: The working hours are fixed and no relaxation is given in terms of the working hours. Flexi hour work timing is missing owing to the shift timings and 
production targets. Lack of abiding to the time leads to reprimand or pay-cuts. Lack of flexibility of timing and task is not comfortable, especially during pregnancy, and after becoming parent.

d) Poor advancement/promotion opportunities: Women are usually side-tracked or pushed backward during decision making. This prevents women from being promoted to higher level. The industry has bias towards men for leadership position. It is found that women are let down in discussions and meeting. Such repeated experiences make women feel underrepresented. Even when they are capable and talented they are pushed backwards, which leads frustrations and irritation at workplace.

e) Lack of challenging/interesting assignments: Less interesting assignments are given to women where the scope of growth is low. Monotonous work or work with less career growth is given to women.

f) Unattractive income/pay: Women are not paid at par with their male counterparts. In performance appraisal, the works done by women are not given the appropriate ratings and monetary benefit. It has been found that the actual credit is usually taken away by men in the group.

g) Risk involved: In the assembly line, paint shop and body shop women should take same safety measures like helmet, gloves, safety shoes, glasses as per the shop-floor requirements. There have been few accidents reported, when women don't follow the same protocol of safety.

\section{Road Ahead}

a) Talent acquisition at entry-level: More women should be appointed at entry level and trained and guided into the industry. This will help to create a strong understanding and develop a good relationship with the industry. Percentage of women in automotive industry is still disappointing. Case studies and success stories should be shown to attract talent.

b) Involvement of women in innovations: Women should be involved in innovations. This will help to develop newer products with new dimensions. It will help to add more fluidity and uniqueness to the design of automotive, which will further generate revenue.

c) Gender sensitization training: There should be training given in the automotive industry regarding gender sensitization. Training is the answer to the change the mindset of people. When a woman walks down the assembly line, the operators should be trained to avoid awkward stares or comment. Training should be given to respect women and value their opinion, especially in meetings, discussions or in Board Room. Similarly, women should be trained to be less emotional at workplace and to focus on performance. This is because feminist consciousness is still under construct and struggling for its recognition [13] 
d) Challenging/Interesting tasks: Women should be given equal opportunities and encouragement to prove themselves. They should be given responsible tasks in the organization.

e) Making gender diversity a mission: The top management should promote gender diversity as a mission. To involve women in every sphere of the industry, and to ensure the protection and safety of the women in their roles. This will help to penetrate diversity throughout the organization. Intersectionality to obfuscate thinking about sexual orientation as a singular, homogenous category. Besides, it spotlights how intersectional positions within the range of sexual minority identities articulate with multiple other dimensions of identity, including gender, racial ethnicity, socioeconomic status, and age [14]

f) Addressing hygiene factor: There should be adequate infrastructure and facilities to support women. It has been found that there are fewer toilets for women in automotive industry which causes inconvenience. Further, sanitary dustbins should also be available.

g) Support during pregnancy: During the stage of pregnancy support should be given to the women like avoidance to going in the assembly line area. If assembly line visit cannot be avoided, then she should be shifted on a temporary basis to some other deskrelated job. Pregnant women should be given to operate in ground floor to avoid inconvenience. The colleagues should treat the pregnant employee with sympathy. The employee should be able to take maternity leave without any stress or indirect pressure. In case of any complications after 6 months of paid maternity leave, women should be given an option of extension of maternity leave with half-pay or without pay.

h) Post-delivery support: After women resume office from their maternity leave, there should be crèche facility in the factory, so that they can resume office comfortably without being worried about their children. Again, the colleagues should treat the employee with sympathy. Since, there would have been a gap of 6 to 7 months of maternity leave, she should be given some time to settle down in the workplace again.

i) Flexi timing: There should be option of flexible work hour. The total productive hours should remain fixed. But there should be an option to change the timings or split the working time especially during the stage of pregnancy and after maternity leave. The option of work from home should be made available at least 2 to 3 days in a month, when visit to the assembly line can be avoided.

j) Strict law in the organization: There should be strict law in the organization in case of any level of harassment. Any complaint raised by the women should be taken seriously and scrutinized. The higher management should impose strict rules through warning, monetary fines, and in extreme cases the person should be fired. There should be zero tolerance to any kind of disrespect, demeaning comments or sexual advances towards women.

k) Avoid "Queen-bee" syndrome: Sheryl Sandberg [9] in her book "Lean In" had mentioned about queen bee syndrome. Women tend to less friendly to other women in the team or department. They prefer to be "Queen-bee" and get all the attention. This is an unhealthy attitude. Women should unite and form cohesive groups so as to 
develop good networking and connectivity in the organization. In automotive industry, it is necessary.

\section{Conclusion}

The good news is that an increasing number of women have entered STEM (Science, Technology, Engineering \& Math) jobs since the 1970's, and gender parity is on the upswing in the auto industry and other technical fields in general. Many automotive industries have strong sexual harassment policies and some of them are having crèche facility also. On the other side, women are also ready to take up challenging job in automotive industry.

A change in mindset of the organization and the community as a whole will make a difference. Making strong policy in the automotive industry for women is certainly the first stepping stone. But, policies are not enough, if the environment in the industry is not conducive and soothing for women to work. Otherwise, it is a daily struggle in the workplace for women. In a study done by the Automotive News, ended with the following statement, "Something has got to change," one woman said. "I'm tired of fighting every day. "This affects the performance of women.

By connecting people from diverse backgrounds it creates an environment that pushes them to move out of their comfort zone. People that come from different cultures, ages or genders tend to think differently, and therefore ideas are always challenged, plans are always tested, and discussions are always richer. When people are faced with diversity on a daily basis, it forces them to see things from a different perspective than they are used to. This can be challenging initially, but once a culture of trust and respect is established within an organization, the discussions that involve a more diverse set of perspectives inevitably lead to greater productivity, creativity and innovation.

The present Government has started the "Make in India" campaign with supports Indian Manufacturing Industry. So, the Indian automotive industry has got support from the Government to improve their manufacturing facilities and infrastructure. It is high time that women are given equal respect and value in the automotive industry. The automotive industry as a whole has a long way to go before achieving true equality between both men and women in positions of power. But, it is not difficult to make it happen. Women are already fueling in the automotive industry and soon women will become half of the number of employees in automotive industry.

\section{References}

2) Acker, J. "Hirearchies, jobs, bodies: a theory of gendered organizations", Gender and Society, Vol. 4 No. 2, pp. 139-158, (1990),

3) Allen, B.J., "Feminist standpoint theory: a black woman's (re)view of organizational socialization", Communication Studies, Vol. 47 No. 4, pp. 257-271, (1996) 
4) Broadbridge, A. " 25 years of retailing; 25 years of change? Reflecting on the position of women managers", Gender in Management: An International Journal, Vol. 25 No. 8, pp. 649660 (2010),

5) Cassier, N. and Reskin, B. (2000), "High hopes: organizational position, employment experiences", And Women's and Men's Promotion Aspirations," Work and Occupations, Vol. 27 No. 4, pp. 438-463

6) Funnell, R. and Chi Dao, H. (2013), "Journeys to the top: women university rectors in Vietnam”, Gender in Management: An International Journal, Vol. 28 No. 5, pp. 299-312

7) Hallstein, D. (2000), "Where standpoint stands now: an introduction and commentary", Women's Studies in Communication, Vol. 23 No. 1, p. 1

8) McKie, L. and Jyrkinen, M. "MyManagement: women managers in gendered and sexualised workplaces", Gender in Management: An International Journal, Vol. 32 No. 2, pp. 98-110, (2017),

9) Pompper, D. "The gender-ethnicity construct in public relations organizations: using feminist standpoint theory to discover Latinas' realities", Howard Journal of Communications, Vol. 18 No. 4, pp. 291-311, (2007)

10) Sandberg, Sheryl Lean In: Women, work and the will to lead Alfred N. Knopf, 2013. Print

11) Sharon Silke Carty, Amy Wilson, Hannah Lutz, Shiraz Ahmed, Jamie LaReau, Katie Burke, Michael Martinez, and Jackie Charniga, "Sexism Alive and Well in Auto Industry," Automotive News, October 22, 2017.

12) Shields, S.A., "Gender: an intersectionality perspective”, Sex Roles, Vol. 59 Nos 5/6, pp. 301-311 (2008)

13) Thompson, B.M. , "Succumbing, surviving, succeeding? Women managers in academia”, Gender in Management: An International Journal, Vol. 30 No. 5, pp. 397-413 (2015)

14) Wanca-Thibault, M. and Tompkins, P.K. "Speaking like a man (and a woman) about organizational communication: feminization and feminism as a recognizable voice", Management Communication Quarterly, Vol. 11 No. 4, pp. 606-621, (1998)

15) Warner, L.R. and Shields, S.A. (2013), "The intersections of sexuality, Gender, and race: identity research at the crossroads", Sex Roles, Vol. 68 Nos 11/12, pp. 803-810

16) Retrieved from: https://www2.deloitte.com/content/dam/Deloitte/us/Documents/manufacturing/us-auto-100leading-women.pdfAccessed on 22nd August 2018

17) Retrieved from:

https://www.sensorsmag.com/components/why-diversity-crucial-to-innovation-automotiveindustry Accessed on 23rd August 2018 
18) Retrieved from

http://www.autonews.com/article/20171022/OEM02/171029978/1320?template=projectxx

Accessed on 24th August 2018

19) Retrieved from :

https://www.news18.com/news/auto/the-role-of-gender-diversity-in-indian-auto-companies1850597.html Accessed on 25th August 2018

20) Retrieved from:

https://indianexpress.com/article/trending/trending-in-india/this-womans-journey-as-anautomotive-designer-will-inspire-you-to-follow-your-dreams-4909428/ Accessed on 26th August 2018।

21) Retrieved from: 10

https://www.catalyst.org/blog/catalyzing/sexual-harassment-enough-enoughAccessed on 27th August 2018

22) Retrieved from :

https://www2.deloitte.com/us/en/pages/manufacturing/articles/women-in-the-globalautomotive-industry.html Accessed on 28th August 2018

23) Retrieved from:

https://auto.economictimes.indiatimes.com/autologue/encourage-engage-prosper-women-inthe-indian-automotive-industry/1361 Accessed on 29th August 2018

24) Retrieved from:

https://thebossmagazine.com/women-automotive-industry/ Accessed on 29th August 2018 